\title{
IMPACT OF BEEDI ROLLING ON LUNG FUNCTIONING- A CROSS SECTIONAL STUDY
}

\author{
Don Gregory Mascarenhas ${ }^{1}$, Glenn Austin Fernandes ${ }^{2}$, Venugopal $^{3}$ \\ ${ }_{1}^{1}$ Assistant Professor, Department of Respiratory Medicine, Father Muller Medical College, Mangalore, Karnataka, India. \\ ${ }_{2}^{2}$ Assistant Professor, Department of General Medicine, Father Muller Medical College, Mangalore, Karnataka, India. \\ ${ }^{3}$ Resident, Department of General Medicine, Father Muller Medical College, Mangalore, Karnataka, India.
}

\section{ABSTRACT}

\section{BACKGROUND}

Occupational health hazard is reported as the tenth leading cause of morbidity and mortality across the globe by the World Health Organization, (WHO). The tobacco epidemic is one of the biggest threats in public health worldwide, killing around 6 million people a year. Beedi rolling is one of the most rampant occupations among housewives in coastal Karnataka as a means of livelihood. Beedi rollers are constantly exposed to the unburnt dust of tobacco, which has become one of the major and commonly found occupational hazards that has been neglected. Occurrence of respiratory disorders such chronic obstructive lung disease, occupational asthma has been reported. However, no protective measures are being taken to prevent health hazards due to tobacco. This study was done to evaluate the lung function tests in asymptomatic beedi rollers for early diagnosis of tobacco related lung disorders. We also wanted to evaluate the pulmonary function of the beedi rollers and create awareness about possibility of respiratory ailments due exposure of tobacco dust.

\section{METHODS}

This was a cross sectional comparative study. Controls were age and gender matched from the general population who were not exposed to any kind of tobacco smoke. The study included 66 beedi rollers in Mangalore. A community-based survey was done and lung function assessment using spirometry was done. Pulmonary function tests (PFT): Forced expiratory volume in one second (FEV1), forced vital capacity (FVC) and the forced expiratory volume in one second as a percentage of FVC (FEV1/FVC), using spirometer were calculated. Based on FEV1/FVC ratio patterns of respiratory impairment whether restrictive/obstructive/mixed is determined. Results were tabulated and statistical analysis was done using SPSS software. Mean, standard deviation and paired $\mathrm{t}$ test were done to determine the significant difference between beedi workers and control subjects, and $\mathrm{p}$ values were calculated. A p value of $<0.05$ was considered statistically significant.

\section{RESULTS}

Among 66 subjects, 51 were females and 15 were males. 15 had mild obstructive pattern (22.7\%), 1 had mild restrictive pattern (1.5\%) and rest 50 subjects had normal lung functioning.

\section{CONCLUSIONS}

There seems to be a linear involvement of lung functioning to duration of tobacco exposure, though the palue is statistically insignificant. Though people who were taken into study were asymptomatic at present, they will have higher risk of developing respiratory problems due to continuous tobacco exposure. Stringent labour rules should be enforced for safeguarding health of these people.

\section{KEY WORDS}

Beedi, Pulmonary Function Test (PFT), Obstructive

HOW TO CITE THIS ARTICLE: Mascarenhas DG, Fernandes GA, Venugopal. Impact of beedi rolling on lung functioning- a cross sectional study. J. Evolution Med. Dent. Sci. 2019;8(28):2219-2222, DOI: 10.14260/jemds/2019/486

\section{BACKGROUND}

Tobacco was introduced in India by the Portuguese in the $17^{\text {th }}$ century. Chewing and smoking tobacco became a household habit in most Portuguese colonies.

British later profited from this booming industry and increased production of tobacco. Tobacco is mainly consumed in the form of cigarettes, beedi, chutta, hookah or betel quid. ${ }^{1}$

'Financial or Other Competing Interest': None.

Submission 26-05-2019, Peer Review 27-06-2019,

Acceptance 05-07-2019, Published 15-07-2019.

Corresponding Author:

Glenn Austin Fernandes,

\#203, Mullernest,

Valencia, Mangalore-575002,

Karnataka, India.

E-mail: glennindia@yahoo.com

DOI: $10.14260 /$ jemds $/ 2019 / 486$
Beedis are hand rolled unfiltered cigarettes. Sun-dried and processed tobacco flakes are rolled in a tendu leaf (Diospyros Melanoxylon) or temburni leaf which are four to eight centimetres in length which is then tied by a cotton thread all around and then closing the non-smoking end. These tendu leaves are non-porous in nature and have low combustibility. ${ }^{2}$

The amount of carbon monoxide and nicotine produced by beedis is much higher than cigarettes. Beedis are much economical as compared to cigarettes and are known as the "poor man's cigarettes". 53 percent of smokers in India smoke bidis. There has been a rising share of cigarette smoking in the recent years especially among the young and literate population. Nevertheless, the production and supply of beedis have not shown any decline owing to this large-scale consumption. ${ }^{1}$

India is the third largest producer of tobacco after China and Brazil. Tobacco used in beedis is different from that used in cigarettes. Beedi tobacco is a rabi crop which is planted in August and harvested in January. The largest producer of 
beedi tobacco is Gujarat, followed by Maharashtra and Karnataka. Beedi industry is one of the largest small scale industries in India. Beedi manufacturing is mainly carried out in Madhya Pradesh, Tamil Nadu, Andhra Pradesh, Karnataka, West Bengal, Bihar, Odisha and Uttar Pradesh. In early 20th century, beedi manufacturing was mainly in factories but now it has mostly shifted to households. Beedi production can be either from unregistered or registered companies. Registered companies like Bharath beedies, Ganesh beedis which produce more than 20 lakh branded beedis are bound by labour rules, need to pay taxes and provide facilities to their labourers like ID, provident fund, housing, education and health. Unregistered companies produce less than twenty lakh beedis per year and are not bound by labour rules. The raw material for beedi, tobacco and tendu leaves are procured by the companies and then handed over to these beedi rollers either directly or through contractors. Over 3 million Indians are employed in the manufacture of beedis and is a cottage industry that is typically done by women in their homes.1,2,3

The steps include soaking, drying and cutting of tendu leaves before filling the leaf with tobacco, rolling the leaf and finally tying the beedi with a thread. ${ }^{2}$

Beedi rollers are constantly exposed to the unburnt dust of tobacco, which has become one of the major and commonly found occupational hazard that is far been neglected. Occurrence of respiratory disorders such chronic obstructive lung disease, occupational asthma have been reported. Occupational health hazard is reported as tenth leading cause of morbidity and mortality across the globe by the World Health Organization, (WHO). The tobacco epidemic is one of the biggest threats in public health worldwide, killing around 6 million people a year. Diagnosis of respiratory illness due to occupational hazard has remained a challenging task. Though the labour rules advice periodic health check-up and providing safety masks for beedi rollers, most companies do not follow them. Many rollers who develop health hazards opt out of manufacturing beedis instead of asking for their rights. As a result, labour rules continue to be only in writing and not practised. This study is conducted in suburbs of Mangalore, a coastal town in Karnataka where beedi rolling is a rampant occupation, especially among homemakers as a means of livelihood. This study is done to know the tobacco related lung disorders and hazards in the presently asymptomatic beedi rollers which can eventually cause morbidity and mortality in the long run if safety issues are not addressed.

\section{Aims and Objectives}

1. To evaluate the pulmonary function of the beedi rollers.

2. To create awareness about possibility of respiratory ailments due exposure of tobacco dust.

\section{METHODS}

\section{Study Design}

Community based, cross sectional comparative study.

\section{Study Population}

Beedi rollers in Mangalore.

\section{Sample Size}

66
70 controls were taken into study. Controls were age and gender matched from the general population who were not exposed to any kind of tobacco smoke.

\section{Study Tools}

After obtaining informed consent, the study population was subjected to a set of questions to know their duration of beedi rolling, usage of safety devices like masks and to rule out any known lung morbidity like Chronic Obstructive Pulmonary Disease, tuberculosis, Interstitial lung diseases. Then they were subjected to Pulmonary Function Tests (PFT) using a hand held spirometer. A maximum of 8 trials was given and Forced Expiratory Volume in one second (FEV1), Forced Vital Capacity (FVC) and the forced expiratory volume in one second as a percentage of FVC (FEV1\%) were calculated. Based on FVC, FEV1 and FEV1/FVC ratio, patterns of respiratory impairment whether restrictive/obstructive/ mixed is determined. An obstructive defect is indicated by a low forced expiratory volume in one second/forced vital capacity (FEV1/FVC) ratio, which is defined as less than $70 \%$ or below the fifth percentile based on data from the Third National Health and Nutrition Examination Survey (NHANES III) in adults. A restrictive pattern is indicated by a FEV1/FVC more than $70 \%$ and FVC below the fifth percentile based on NHANES III data. If both the FEV1/FVC ratio and the FVC are low, the patient has a mixed defect. ${ }^{4}$

Results were tabulated and statistical analysis was done using SPSS software. Mean, standard deviation and Paired t test were done to determine the significant difference between beedi workers and control subjects, and $p$ value were calculated. A $\mathrm{p}$ value of $<0.05$ was considered statistically significant.

\section{Inclusion Criteria}

Beedi workers who were currently involved in beedi rolling and exposed to tobacco dust for more than 2 years were included in the study.

\section{Exclusion Criteria}

Beedi Rollers with-

1. Cough/Acute respiratory illness.

2. Diagnosed cases of active tuberculosis/COPD/asthma.

3. Smokers/ reformed smokers.

4. Those who do not consent for the study.

\section{RESULTS}

Beedi rolling was most commonly done by homemakers living in suburbs of Mangalore. Hence among 66 subjects, 51 were females, 15 were males.

\begin{tabular}{|c|c|c|}
\hline & Frequency & Percentage \\
\hline Female & 51 & 77.3 \\
\hline Male & 15 & 22.7 \\
\hline Total & 66 & 100 \\
\hline \multicolumn{3}{|c|}{ Table 1. Gender Distribution } \\
\hline PFT of Workers & Frequency & Percentage \\
\hline Normal & 50 & 75.8 \\
\hline Abnormal & 16 & 24.2 \\
\hline Total & 66 & 100.0 \\
\hline \multicolumn{3}{|c|}{ Table 2. Pulmonary Function Test Pattern } \\
\hline
\end{tabular}




\begin{tabular}{|c|c|c|c|}
\hline Age (In Years) & Normal PFT & Abnormal & Total \\
\hline $21-40$ & 6 & 4 & 10 \\
\hline $41-60$ & 28 & 6 & 34 \\
\hline 60 and above & 16 & 6 & 22 \\
\hline Total & $\mathbf{5 0}$ & $\mathbf{1 6}$ & $\mathbf{6 6}$ \\
\hline \multicolumn{3}{|c|}{ Table 3. Age Wise Distribution } \\
\hline
\end{tabular}

\begin{tabular}{|c|c|c|c|c|c|}
\hline & Type & $\begin{array}{c}\text { No. of } \\
\text { Subjects }\end{array}$ & Mean & $\begin{array}{c}\text { Std. } \\
\text { Deviation }\end{array}$ & $\begin{array}{c}\text { t Test p } \\
\text { Value }\end{array}$ \\
\hline \multirow{2}{*}{ BMI } & Normal PFT & 50 & 22.686 & 4.7724 & \multirow{2}{*}{.105} \\
\cline { 2 - 5 } & Abnormal PFT & 16 & 20.481 & 4.2840 & \\
\hline $\begin{array}{c}\text { Years of Beedi } \\
\text { Rolling }\end{array}$ & Normal PFT & 50 & 9.30 & 3.321 & \multirow{2}{*}{.708} \\
\cline { 2 - 4 } & Abnormal PFT & 16 & 9.69 & 4.362 & \\
\hline \multicolumn{7}{|c|}{ Table 4. Correlation of BMI and Duration of Tobacco } \\
Exposure Between Subjects with Normal and Abnormal PFT \\
\hline
\end{tabular}

40 were Hindus, 24 were Muslims and 2 were Christians among the experimental study population.

Majority of the experimental study subjects had tobacco exposure of more than 8 years.

Most subjects rolled a minimum of 500 beedis per day, 6 days a week.

15 had obstructive pattern $(22.7 \%), 1$ had restrictive pattern $(1.5 \%)$ and rest 50 subjects had normal lung functioning. All control subjects had a normal PFT.

Majority of the study population aged between 41 to 60 years.

Mean Body mass index of subjects who had abnormal PFT was 20.48 as compared to 22.68 among subjects with normal PFT. BMI of controls was 22.8. p value was 0.105 which means this was statistically insignificant.

Mean duration of beedi rolling was 9.3 years among subjects with normal PFT as compared to 9.69 among subjects with abnormal PFT. Though rollers with abnormal PFT had more exposure to tobacco than the rollers with normal PFT, $p$ value was 0.708 which is statistically insignificant. Most of the studies show a correlation between duration of tobacco exposure and lung functioning. As the duration increases, decline in lung function increases.

\section{DISCUSSION}

As seen in the results, most of our experimental study population were females, majority being aged between 41-60 years. Most had a BMI between 20 to 23. Mean duration of tobacco exposure was 9.3 years among subjects who had normal PFT and 9.69 among subjects with abnormal pattern. All subjects worked for registered factories, but none were provided face masks for self-protection against tobacco dust. They were neither aware of the labour laws nor regarding the need of usage of safety measures like face masks while working to prevent inhalation of tobacco dust. Subjects who had a abnormal PFT were advised to undergo further tests like chest X-ray, DLCO and blood levels of nicotine to rule out occupational lung disorders. The entire experimental study population were advised regarding occupational lung disorders, labour rules, safety in occupational places and prevention of health hazards.

A study done by Banu et al in Salem and Dharmapuri evaluated 182 beedi workers using a questionnaire and flow volume spirometer. They found that $16 \%$ of rollers had obstructive, $7 \%$ had restrictive and $10 \%$ of workers had mixed disorders. They stressed the need to implement strict measures to prevent health hazards due to raw tobacco. ${ }^{5}$

A study done by B. P. Chattopadhyay et al in 2006 in Kolkata on 51 beedi rollers working in unorganised sector showed obstructive pattern in $11.76 \%$ cases and equal percentage of restrictive and combined pattern, each being $5.88 \%$ They found a higher incidence of declining lung functioning with age and duration of work exposure. 6

A study by Hegde et al on 32 tobacco workers found that there is decline in lung function in tobacco workers as compared to controls. They tried intervention by using surgical face masks which proved non beneficial to the tobacco workers in terms of lung functioning. ${ }^{7}$

A study done by Zahid et al in 2008 for one year involving smoking and non-smoking tobacco workers in Rangpur, Bangladesh showed that tobacco workers had significantly lower percentage of predicted values of FVC, FEV1 and FEV1/FVC than control subjects. Also smoking tobacco workers had lower lung functioning as compared to nonsmoking tobacco workers. ${ }^{8}$

A study by Ignacak A et al "Influence of tobacco dust on the respiratory system and selected immunological parameters" found that FEV1/VC was significantly lower in tobacco workers chronically exposed to tobacco dust than in the control group. ${ }^{9}$

In Contrast to above results, a study by Osim EE in 1998 in Zimbabwe on "Lung function of Zimbabwean farm workers exposed to flue curing and stacking of tobacco leaves" found restrictive lung defects in most workers and concluded that restrictive lung defect in the tobacco farm workers may be attributed to long-term exposure to flue curing and stacking of tobacco leaves. ${ }^{10}$

There are a lot of legislations with regard to beedi industry. The beedi and cigar workers act of 1966 has an objective of regulating conditions of employment of workers employed in beedi manufacturing unit. According to this act, state government appoints inspectors who would conduct regular inspection as required of industrial premises to ensure that the provisions of the Act are complied along with Cleanliness, adequate ventilation and no overcrowding. The contract labour act of 1970 which applies to any establishment of twenty or more contract employees has provisions of penalty for offenses by contractor which can be jail term of 3 years or fine up to 1000 rupees. There are still more legislations pertaining to this industry, but health hazards are grossly ignored by the contractors. It was even found that children used to help their parents in beedi rolling in spite of strict rules against child labour. Most rules are being ignored owing to lack of regular inspection because of which offenders get away. This has led to large number of morbidities. Many workers could not be taken into our study owing to their symptoms of cough, wheezing and breathlessness which could have been due to tobacco dust.

If these workers were taken into study, we would have got a varied lung functioning, the incidence of occupational lung disorders and much more data regarding tobacco related effects on health. A study conducted by Singh et al in 2014 in Uttar Pradesh among 214 beedi workers in the age group of 20-75 showed that 22.68 percent had respiratory problems. ${ }^{11}$ Many more studies are required in this direction to understand more regarding effects of inhalation of tobacco and to establish a causal and temporal relationship.

\section{CONCLUSIONS}

There seems to be a linear involvement of lung functioning to age and duration of tobacco exposure, though the $p$ value is statistically insignificant. As age increases, the lung function 
tends to decline which might have been a confounding factor. Though people who were taken into study were asymptomatic at present, they will have higher risk of developing respiratory problems due to continuous tobacco exposure. They were advised to use protective masks, preferably N95 masks to avoid tobacco related health hazards. Most of our study population were hired by registered companies for beedi rolling, but through contractors. They were not aware of rules and regulations pertaining to this industry. They were also not aware of health hazards and need for safety measures to protect against development of occupational lung disorders. It is the responsibility of the registered tobacco companies to provide basic amenities and safety measures to their labourers to prevent lung disorders thereby reducing morbidity. Stringent labour rules should be enforced for safeguarding health of these people and government should penalise the defaulters which is the only way to do away with defaulters. Government must also ensure that tobacco related companies do strict medical check-up before providing employment to avoid hiring workers who already have pre-existing lung diseases like chronic obstructive lung disorder, interstitial lung disease etc., which can reduce lung functioning per se.

This study is limited by the small sample size and it being a cross sectional study. More studies are needed regarding non-smoking/passive tobacco related hazards for better understanding of the gravity of situation.

\section{REFERENCES}

[1] John P. Beedi Industry and Welfare of Workers in India. Review of policies and literature. New Delhi, 2015.

[2] John S. History and culture of Bidis in India: production, employment, marketing and regulations. In: Gupta PC, Asma S, eds. Bidi smoking and public health. New Delhi, Ministry of Health and Family Welfare, Government of India, 2008.
[3] Making ends meet: Bidi workers in India Today. Geneva: International Labour Office. http://staging.ilo.org/public/libdoc/ilo/2001/101B0 9_362_engl.pdf

[4] Johnson JD, Theurer WM. A stepwise approach to the interpretation of pulmonary function tests. Am Fam Physician 2014;89(5):359-66.

[5] Banu KK, Sitalakshmi R, Padmavathi R. Pulmonary functions among Beedi rolling industry workers of South India. A cross sectional study. IJBAR 2014;(05):31-4.

[6] Chattopadhyay BP, Kundu S, Mahata A, et al. A study to assess the respiratory impairments among the male Beedi workers in unorganized sectors. Indian J Occup Environ Med 2006;10(2):69-73.

[7] Hedge VM, Ajith S, Shetty K. A study to evaluate respiratory symptoms and lung function impairment in Beedi workers and usefulness of protective mask in reducing respiratory symptoms. Int J Physiother \& Res 2015;3(2):986-91.

[8] Zahid ATMZR, Bari MA, Sarkar CR, et al. FVC, FEV1 and FEV1\% in male tobacco industry workers. J Bangladesh Soc Physiol 2011;6(2):90-3.

[9] Ignacak A, Guzik TJ, Gorski L, et al. Influence of tobacco dust on the respiratory system and selected immunological parameters. Przegl Lek 2002;59(10):789-92.

[10] Osim EE, Musabayane CT, Mufunda J. Lung function of Zimbabwean farm workers exposed to flue curing and stacking of tobacco leaves. S Afr Med J 1998;88(9):1127-31.

[11] Singh JK, Rana SVS, Mishra N. Occupational health problems amongst women Beedi rollers in Jhansi, Bundelkhand region, Uttar Pradesh. Journal of Ecophysiology and Occupational Health 2014;14(12):17-22. 